\title{
Glycolic acid in hydrogen peroxide-based slurry for enhancing copper chemical mechanical polishing
}

\author{
Tzu-Hsuan Tsai ${ }^{\mathrm{a}, *}$, Yung-Fu Wu ${ }^{\mathrm{b}}$, Shi-Chern Yen ${ }^{\mathrm{b}}$ \\ a Department of Chemical Engineering, Northern Taiwan Institute of Science and Technology, No. 2, Xueyuan Rd., \\ Beitou, Taipei 112, Taiwan, R.O.C. \\ ${ }^{\mathrm{b}}$ Department of Chemical Engineering, National Taiwan University, Taipei 106, Taiwan
}

Received 14 August 2004; accepted 30 October 2004

Available online 19 November 2004

\begin{abstract}
The effects of glycolic acid (GCA) added into hydrogen peroxide $\left(\mathrm{H}_{2} \mathrm{O}_{2}\right)$ or urea-hydrogen peroxide $\left(\mathrm{U}-\mathrm{H}_{2} \mathrm{O}_{2}\right)$ slurries on $\mathrm{Cu}$-CMP performance were investigated. Experiments showed that GCA could prevent $\mathrm{H}_{2} \mathrm{O}_{2}$ or U$\mathrm{H}_{2} \mathrm{O}_{2}$ from rapid decomposition and increase the active peroxide lifetime of the slurries. In addition, electrochemical studies from polarization and impedance experiments verified that copper removal efficiency could be enhanced by use of GCA. Meanwhile, a valid equivalent circuit for $\mathrm{Cu}$-CMP system was proposed, and the fitting results provided a good index to surface planarization. Furthermore, GCA could shorten the range of isoelectric points between $\mathrm{Cu}$ film and $\alpha-\mathrm{Al}_{2} \mathrm{O}_{3}$ abrasives. After a post cleaning, the particle contamination thus could be reduced due to the electrostatic repulsion. Our study proved that adding GCA into the $\mathrm{U}-\mathrm{H}_{2} \mathrm{O}_{2}$ slurries with BTA could further improve the $\mathrm{Cu}-\mathrm{CMP}$ performance.
\end{abstract}

(c) 2004 Elsevier B.V. All rights reserved.

Keywords: Glycolic acid; Urea-hydrogen peroxide; Slurry; Copper; Chemical mechanical polishing

\section{Introduction}

Chemical mechanical polishing (CMP) of metal is widely recognized as the key technique to obtain global planarization for copper multilevel interconnection in IC manufacturing [1]. However,

\footnotetext{
${ }^{*}$ Corresponding author. Tel.: +886228927154x8041; fax: +886228960255 .

E-mail address: tzhtsai@ntu.edu.tw (T.-H. Tsai).
}

the planarization mechanisms of metal CMP involve complicated chemical reactions and physical actions. So it is difficult to control the CMP performance, especially for a high corrosion-sensitivity metal like $\mathrm{Cu}$. According to different slurry components, the planarization mechanisms of metal CMP can be summarized as the following two types. The first one is that the metal surface may be polished with a dissolution-type slurry in which no surface film forms. In this case, the CMP 
process proceeds by the mechanical removal and chemical dissolution of metal itself [2]. In the second type of mechanisms, a thin abradable layer is continuously formed on metal surface by the reactions of metal and slurry components. These slurry components may include oxidants, inhibitors and other film-forming agents. The thin abradable layer is then scanned away rapidly by the mechanical action or dissolves in the slurry with a chelating agent. Once the mechanical polishing process has stopped, a thin passive film remains on the surface and inhibits the proceeding of wet etching [3]. Therefore, controlling CMP process to reach global planarization is much easier due to this mechanism.

The chemical components and properties of slurry determine the $\mathrm{Cu}$-CMP performance principally. As a result, many studies devoted to the development of copper slurries with high planarization ability and CMP efficiency. According to the second mechanism mentioned above, oxidants with high oxidizing ability and low contamination should be required to form a passive film on $\mathrm{Cu}$ surface. Hydrogen peroxide $\left(\mathrm{H}_{2} \mathrm{O}_{2}\right)$ is a widely used example at present [4,5]. However, $\mathrm{H}_{2} \mathrm{O}_{2}$ decomposes to $\mathrm{H}_{2} \mathrm{O}$ and $\mathrm{O}_{2}$ easily, and this decomposition will result in the slurry transport issues, unstable CMP performance and short shelf lifetime. Recently, urea-hydrogen peroxide (U$\mathrm{H}_{2} \mathrm{O}_{2}$ ) has been proposed as the oxidant for $\mathrm{Cu}$ CMP slurries due to its less self-decomposition and better oxidizing performance during CMP [6].

Also, Kaufman and Kistler [7] reported that organic acids can be added into metal slurries to enhance CMP performance by acting as $\mathrm{pH}$ adjusters or chelating agents. On the other hand, many researchers have examined the further efficiency of organic acids, and it was found that the action of organic acids would depend on the different CMP conditions. For instance, in 1999, Hu et al. [8] indicated that citric acid can inhibit $\mathrm{Cu}$ corrosion in $\mathrm{HNO}_{3}$ slurries, and Zhang et al. [9] found that citric acid can prevent the alumina-particle deposition on tungsten surface. Even though many organic acids, such as acetic acid [10], oxalic acid [11], ethylenediamine tetraacetic acid (EDTA) [12] and amino acid $[13,14]$ have been extensively studied, glycolic acid (GCA) has never been used.
As known, GCA is easy handling, water-soluble, biodegradable, non-volatile and can efficiently chelate the metal. Therefore, the objective of this paper is to investigate the effect of GCA added into $\mathrm{U}-\mathrm{H}_{2} \mathrm{O}_{2}$ slurries on electrochemical behaviors of $\mathrm{Cu}$ CMP. In addition to the measurement of polarization curves, the electrochemical impedance spectroscopy (EIS) was also obtained, and the equivalent circuit of surface reactions during $\mathrm{Cu}$ CMP was proposed. Although the equivalent circuits of Al have been discussed [15], fewer studies examined that in $\mathrm{Cu} \mathrm{CMP}$. In this study, the specific role of GCA and the information of the equivalent circuit for CMP in $\mathrm{U}-\mathrm{H}_{2} \mathrm{O}_{2}$-based slurries were explored. Our experiments proved that GCA could improve Cu-CMP efficiency, and the planarization mechanisms of $\mathrm{Cu} C \mathrm{CMP}$ could be described well by the electrochemical methods.

\section{Experimental}

Commercial pure $\mathrm{Cu}$ sheets with 0.3 -mm thickness were used, and the dimension of each specimen was $1 \times 1 \mathrm{~cm}^{2}$ for electrochemical measuring. In addition, 3-in. wafers with an electroplated $\mathrm{Cu}$ film were polished to obtain removal rates and surface roughness. All specimens were degreased by the cathode electrochemical method at $6 \mathrm{~V}$ for $20 \mathrm{~s}$, and then were cleaned in $3 \mathrm{wt} \%$ $\mathrm{H}_{2} \mathrm{SO}_{4}$ solution followed by deionized (DI) water rinsing. Afterward, the samples were dried in nitrogen gas and transferred to the electrochemical measuring equipment or polishing machine. The slurry was prepared by use of 50-nm alumina particles $\left(\alpha-\mathrm{Al}_{2} \mathrm{O}_{3}\right)$, and its solid concentration in the slurry was fixed at $5 \mathrm{wt} \%$ for all of the experiments. To investigate the effects of different chemical components on $\mathrm{Cu} \mathrm{CMP}$, we prepared the slurries by analytical grade reagents, including urea-hydrogen peroxide $\left(\mathrm{U}-\mathrm{H}_{2} \mathrm{O}_{2}\right)$, benzotriazole (BTA) and glycolic acid (GCA).

For the purpose to compare the stability of solutions, $5 \mathrm{wt} \% \mathrm{U}-\mathrm{H}_{2} \mathrm{O}_{2}$ and $1.8 \mathrm{wt} \% \mathrm{H}_{2} \mathrm{O}_{2}$, with the equal level of peroxide in solutions, were periodically analyzed by titration with $1 \mathrm{wt} \%$ potassium permanganate solution to determine the peroxide activity. An acoustic spectrometer, model 
DT-1200, was used to determine the zeta potentials of materials in different $\mathrm{pH}$ values adjusted by $\mathrm{HNO}_{3}$ or $\mathrm{NH}_{4} \mathrm{OH}$. Dipping experiments were conducted to determine the particle contamination on $\mathrm{Cu}$ surface. For dipping experiments, 300-nm $\alpha-\mathrm{Al}_{2} \mathrm{O}_{3}$ particles were used in slurries for SEM observation. After dipped in slurries for $30 \mathrm{~s}, \mathrm{Cu}$ samples were rinsed gently with DI water prior to SEM study.

The electrochemical test-cell was composed of $\mathrm{Cu}$ working electrode, platinum counter electrode and $\mathrm{Ag} / \mathrm{AgCl}$ reference electrode, with a Luggin probe. The downward pressure and the rotating speeds during abrasion were 5 psi and $100 \mathrm{rpm}$, respectively. The dc electrochemical experiments were conducted by use of a potentiostat of EG\&G, model 273A, while the corrosion software of EG\&G, model 352, was adopted for electrochemical calculations. The dc polarization curves with a voltage scan rate of $5 \mathrm{mV} / \mathrm{s}$ were selected to measure the corrosion current densities and potential. Meanwhile, the corrosion current density was converted to the corresponding corrosion rate (CR) in $\mathrm{nm} / \mathrm{min}$ according to Faraday's law. In addition, EIS measuring was performed with an electrochemical interface system of Solartron, FRA 1260 and 1286, and a small amplitude perturbation of $10 \mathrm{mV}$ in a sinusoidal wave was applied with the operated frequency, $10^{5}-10^{-2} \mathrm{~Hz}$, to ensure the linearity for impedance analysis.

For polishing experiments, a Lapmaster LM-51 polisher, operated at $80 \mathrm{rpm} / 60 \mathrm{rpm}$ of the platen/ carrier rotating speeds, was used with the polishing pad of IC 1000/SUBA IV supplied by Rodel. Before CMP, the slurry had to be stirred in a mixer to maintain the slurry suspension for the test period. During CMP, the slurry was delivered to the gap between $\mathrm{Cu}$ and the pad with a flow rate of $100 \mathrm{ml} / \mathrm{min}$. The removal rate (RR) was calculated from the weight loss of $\mathrm{Cu}$ sheets before and after 5-min polishing, and the results were obtained by the average of three tests. Before or after CMP, the surface morphology of specimens was characterized by an atomic force microscope (AFM), and the surface rms-roughness $\left(R_{\mathrm{q}}\right)$ was calculated by the software package.

\section{Results and discussion}

\subsection{Durability of slurries}

As mentioned above, the oxidant acts an important role of film-formation in CMP slurry. In this study, we chose two peroxides, $\mathrm{H}_{2} \mathrm{O}_{2}$ and $\mathrm{U}$ $\mathrm{H}_{2} \mathrm{O}_{2}$, as the oxidants. Table 1 lists the active percentages of $\mathrm{H}_{2} \mathrm{O}_{2}$ and $\mathrm{U}-\mathrm{H}_{2} \mathrm{O}_{2}$, relative to their initial values, and the $\mathrm{pH}$ values in various hydrogen peroxide-based solutions. The results indicated that the active peroxide percentage in $1.8 \mathrm{wt} \%$ $\mathrm{H}_{2} \mathrm{O}_{2}$ solution degraded at a faster rate than that in $5 \mathrm{wt} \% \mathrm{U}-\mathrm{H}_{2} \mathrm{O}_{2}$ solution, but their $\mathrm{pH}$ values were similar. Additionally, the degradation rates of the active peroxide percentage showed large

Table 1

Changes of active peroxide percentage (\%) and $\mathrm{pH}$ value with time in various $\mathrm{H}_{2} \mathrm{O}_{2}$ or $\mathrm{U}-\mathrm{H}_{2} \mathrm{O}_{2}$ slurries

\begin{tabular}{|c|c|c|c|c|c|c|c|}
\hline & Time $(\mathrm{h})$ & 0 & 10 & 50 & 100 & 250 & 500 \\
\hline \multirow[t]{2}{*}{$1.8 \mathrm{wt}^{0} \% \mathrm{H}_{2} \mathrm{O}_{2}$} & $\%$ & 100.0 & 96.35 & 75.16 & 57.42 & 41.99 & 33.44 \\
\hline & $\mathrm{pH}$ & 5.56 & 5.52 & 5.31 & 5.45 & 5.03 & 5.18 \\
\hline \multirow[t]{2}{*}{$1.8 \mathrm{wt} \% \mathrm{H}_{2} \mathrm{O}_{2}+1 \mathrm{wt}^{0} \% \mathrm{NH}_{4} \mathrm{OH}$} & $\%$ & 100.0 & 23.75 & 20.12 & 18.15 & 16.41 & 15.08 \\
\hline & $\mathrm{pH}$ & 10.03 & 10.21 & 9.78 & 9.65 & 9.41 & 9.32 \\
\hline \multirow{2}{*}{$1.8 \mathrm{wt}^{\circ} \% \mathrm{H}_{2} \mathrm{O}_{2}+1 \mathrm{wt} \% \mathrm{GCA}$} & $\%$ & 100.0 & 96.01 & 83.24 & 71.31 & 64.02 & 57.88 \\
\hline & $\mathrm{pH}$ & 1.98 & 2.03 & 2.07 & 2.13 & 2.02 & 2.21 \\
\hline \multirow[t]{2}{*}{$5 \mathrm{wt} \% \mathrm{U}-\mathrm{H}_{2} \mathrm{O}_{2}$} & $\%$ & 100.0 & 98.52 & 93.02 & 91.04 & 89.75 & 87.48 \\
\hline & $\mathrm{pH}$ & 5.87 & 5.65 & 5.89 & 5.76 & 5.81 & 5.92 \\
\hline \multirow[t]{2}{*}{$5 \mathrm{wt} \% \mathrm{U}-\mathrm{H}_{2} \mathrm{O}_{2}+1 \mathrm{wt} \% \mathrm{NH}_{4} \mathrm{OH}$} & $\%$ & 100.0 & 76.12 & 52.43 & 48.21 & 35.02 & 31.80 \\
\hline & $\mathrm{pH}$ & 10.62 & 10.58 & 10.64 & 10.47 & 10.32 & 10.20 \\
\hline \multirow[t]{2}{*}{$5 \mathrm{wt} \% \mathrm{U}-\mathrm{H}_{2} \mathrm{O}_{2}+1 \mathrm{wt} \% \mathrm{GCA}$} & $\%$ & 100.0 & 97.82 & 96.01 & 94.23 & 93.31 & 91.59 \\
\hline & $\mathrm{pH}$ & 2.04 & 2.10 & 2.08 & 2.11 & 1.94 & 2.07 \\
\hline
\end{tabular}


variations when the $\mathrm{U}-\mathrm{H}_{2} \mathrm{O}_{2}$ or $\mathrm{H}_{2} \mathrm{O}_{2}$-based solutions were mixed with $\mathrm{NH}_{4} \mathrm{OH}$ or GCA. In $\mathrm{Cu}-\mathrm{CMP}$ slurry, $\mathrm{NH}_{4} \mathrm{OH}$ has been a well-known chelating agent. However, it was found the active peroxide percentage of $5 \mathrm{wt} \% \mathrm{H}_{2} \mathrm{O}_{2}$ solution with $1 \mathrm{wt} \% \mathrm{NH}_{4} \mathrm{OH}$ reduced to $23.75 \%$ of its initial value after only $10 \mathrm{~h}$. Even though $\mathrm{H}_{2} \mathrm{O}_{2}$ was replaced by $\mathrm{U}-\mathrm{H}_{2} \mathrm{O}_{2}$, the peroxide activity of 5 wt $\%$ U- $\mathrm{H}_{2} \mathrm{O}_{2}$ solution with $1 \mathrm{wt} \% \mathrm{NH}_{4} \mathrm{OH}$ also reduced to $31.8 \%$ after $500 \mathrm{~h}$. On the contrary, the addition of GCA, another chelating agent for $\mathrm{Cu}$, could enhance the durability of slurries. After $500 \mathrm{~h}$, the active peroxide percentage still exhibited a high level, $91.59 \%$, for the $5 \mathrm{wt} \% \mathrm{U}-\mathrm{H}_{2} \mathrm{O}_{2}$ solution with $1 \mathrm{wt} \%$ GCA. Also, the $5 \mathrm{wt} \% \mathrm{H}_{2} \mathrm{O}_{2}$ solution with $1 \mathrm{wt} \%$ GCA had higher peroxide activity than that with $\mathrm{NH}_{4} \mathrm{OH}$. This showed that using GCA as a chelating agent instead of $\mathrm{NH}_{4} \mathrm{OH}$ could form a stable solution with a longer shelf lifetime for hydrogen peroxide-based CMP slurry.

\subsection{Polarization curves}

The abrasion effect on the polarization curves of $\mathrm{Cu}$ in various slurries are shown in Fig. 1 and Fig. 2, and their corresponding corrosion parameters and $\mathrm{Cu}$ removal rates (RR) are all listed in
Table 2. The first thing noticeable is the difference between polarization curves of Fig. 1, especially the corrosion potential drop after abrasion $\left(\Delta E_{\mathrm{d}}\right)$. It is obvious that $\Delta E_{\mathrm{d}}$ in $1 \mathrm{wt} \%$ GCA slurry was smaller than that in $5 \mathrm{wt} \% \mathrm{U}-\mathrm{H}_{2} \mathrm{O}_{2}$. As reported [16], the potential drop is attributed to the change on sample surface from the formation of passive film to its removal. Therefore, as shown in Fig. 1, the larger $\Delta E_{\mathrm{d}}$ in $5 \mathrm{wt} \% \mathrm{U}_{-} \mathrm{H}_{2} \mathrm{O}_{2}$ illustrated a faster formation and a quicker removal of the passive film on $\mathrm{Cu}$ surface. On the other hand, $\mathrm{Cu}$ in $1 \mathrm{wt} \%$ GCA with a higher anodic current density, relative to $5 \mathrm{wt} \% \mathrm{U}-\mathrm{H}_{2} \mathrm{O}_{2}$, exhibited a faster dissolution rate of $\mathrm{Cu}$ due to the chelating action between $\mathrm{Cu}$ surface and GCA. In further comparison with the corrosion parameters in Table 2, the corrosion potential and corrosion current density were both higher in $5 \mathrm{wt} \% \mathrm{U}-\mathrm{H}_{2} \mathrm{O}_{2}$ than those in $1 \mathrm{wt} \%$ GCA. This was attributed to the $\mathrm{Cu}$ with higher oxidation state and greater oxidizing rate in $\mathrm{U}-\mathrm{H}_{2} \mathrm{O}_{2}$ solution. Thus, it could be shown again that $\mathrm{U}-\mathrm{H}_{2} \mathrm{O}_{2}$ owned a strong oxidizing action for $\mathrm{Cu}$, and the formed passive film could protect $\mathrm{Cu}$ from deeper corrosion.

When $5 \mathrm{wt} \% \quad \mathrm{U}-\mathrm{H}_{2} \mathrm{O}_{2}$ was mixed with $1 \mathrm{wt} \%$ GCA, $\Delta E_{\mathrm{d}}$ decreased drastically but the anodic current density of $\mathrm{Cu}$ increased as shown in

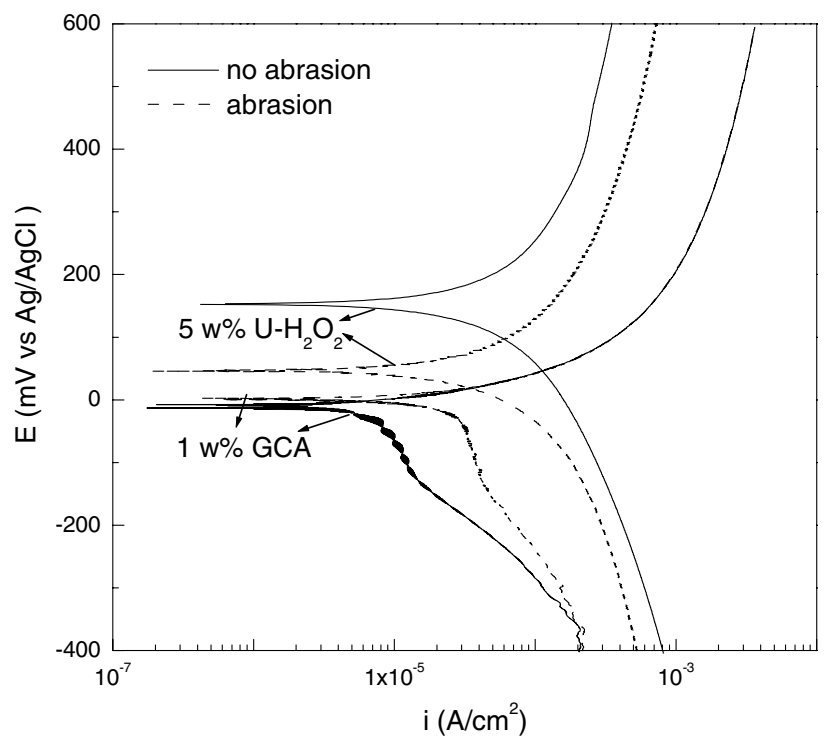

Fig. 1. Effect of abrasion on polarization curves for $\mathrm{Cu}$ in $5 \mathrm{wt} \% \mathrm{U}-\mathrm{H}_{2} \mathrm{O}_{2}$ or $1 \mathrm{wt} \%$ GCA slurry (abrasion: $5 \mathrm{psi}$ and $100 \mathrm{rpm}$ ). 


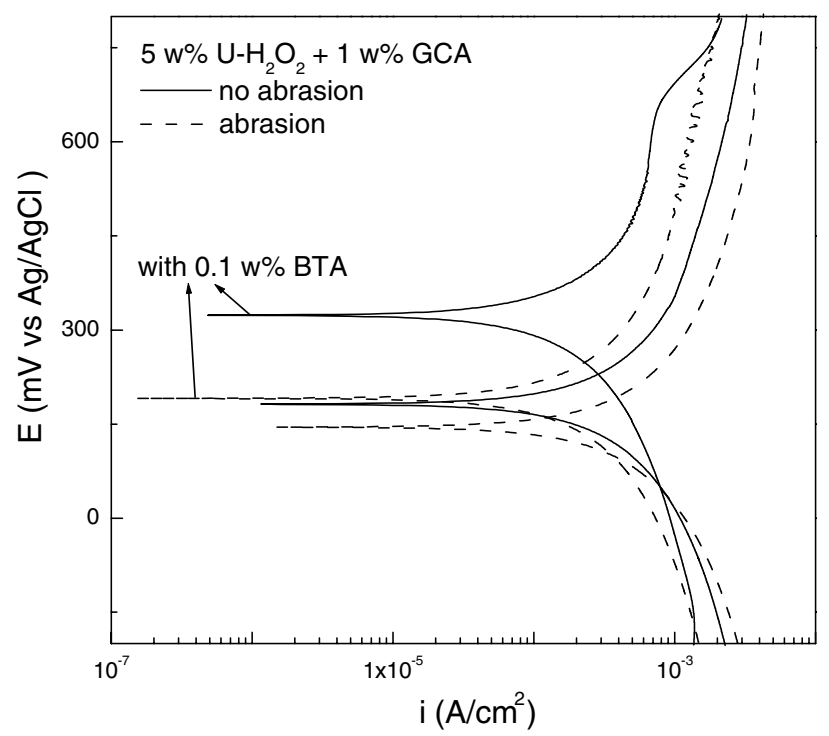

Fig. 2. Effects of abrasion and BTA on polarization curves for $\mathrm{Cu}$ in $5 \mathrm{wt} \% \mathrm{U}-\mathrm{H}_{2} \mathrm{O}_{2}$ with $1 \mathrm{wt} \%$ GCA slurries (abrasion: 5 psi and 100 rpm).

Table 2

Summary of corrosion parameters and removal rates (RR) of $\mathrm{Cu}$ in various slurries

\begin{tabular}{|c|c|c|c|c|c|c|c|}
\hline \multirow[t]{2}{*}{ Slurry } & \multicolumn{2}{|c|}{ No abrasion } & \multicolumn{2}{|l|}{ Abrasion } & \multirow[t]{2}{*}{$\Delta E_{\mathrm{d}}^{\mathrm{a}}(\mathrm{mV})$} & \multirow[t]{2}{*}{$\mathrm{RR}(\mathrm{nm} / \mathrm{min})$} & \multirow[t]{2}{*}{$\mathrm{CR}(\mathrm{nm} / \mathrm{min})$} \\
\hline & $E_{\text {corr }}(\mathrm{mV})$ & $i_{\text {corr }}\left(\mathrm{A} / \mathrm{cm}^{2}\right)$ & $E_{\text {corr }}(\mathrm{mV})$ & $i_{\text {corr }}\left(\mathrm{A} / \mathrm{cm}^{2}\right)$ & & & \\
\hline $5 \mathrm{wt} \% \mathrm{U}-\mathrm{H}_{2} \mathrm{O}_{2}$ & 153 & $1.13 \times 10^{-4}$ & 46 & $1.33 \times 10^{-4}$ & 107 & 472.63 & 2.92 \\
\hline $1 \mathrm{wt} \% \mathrm{GCA}$ & -8 & $1.42 \times 10^{-5}$ & 3 & $4.48 \times 10^{-5}$ & -11 & 184.30 & 1.07 \\
\hline $5 \mathrm{wt} \% \mathrm{U}-\mathrm{H}_{2} \mathrm{O}_{2}+1 \mathrm{wt} \% \mathrm{GCA}$ & 182 & $4.60 \times 10^{-4}$ & 145 & $8.85 \times 10^{-4}$ & 37 & 605.82 & 19.59 \\
\hline $\begin{array}{l}5 \mathrm{wt} \% \mathrm{U}-\mathrm{H}_{2} \mathrm{O}_{2}+1 \mathrm{wt} \% \mathrm{GCA}+ \\
0.1 \mathrm{wt} \% \text { BTA }\end{array}$ & 323 & $9.63 \times 10^{-5}$ & 191 & $1.53 \times 10^{-4}$ & 132 & 594.14 & 3.37 \\
\hline
\end{tabular}

${ }^{\text {a }} \Delta E_{\mathrm{d}}: E_{\text {corr(no abrasion) }}-E_{\text {corr(abrasion) }}$.

Fig. 2. It resulted from the thinning passive film on $\mathrm{Cu}$ surface by the chelating action of GCA, so the $\mathrm{Cu}$ consumption was enhanced by both chelating and polishing. Thus, as listed in Table 2, the high corrosion rate, $19.59 \mathrm{~nm} / \mathrm{min}$, and removal rate, $605.82 \mathrm{~nm} / \mathrm{min}$, were obtained in the mixed slurry, $5 \mathrm{wt} \% \mathrm{U}-\mathrm{H}_{2} \mathrm{O}_{2}$ and $1 \mathrm{wt} \%$ GCA. Furthermore, Fig. 2 also shows that $\Delta E_{\mathrm{d}}$ increased substantially by adding $0.1 \mathrm{wt} \%$ BTA into $5 \mathrm{wt} \% \mathrm{U}-\mathrm{H}_{2} \mathrm{O}_{2}$ and 1 wt $\%$ GCA slurry even though the current density still maintained a low level. It indicates that $\mathrm{Cu}$ in $5 \mathrm{wt} \% \mathrm{U}-\mathrm{H}_{2} \mathrm{O}_{2}$ slurry with $1 \mathrm{wt} \%$ GCA and $0.1 \mathrm{wt} \%$ BTA showed the high mechanical sensitivity and good anti-corrosion capability. As a result, the $\mathrm{Cu}$ removal rate attained $594.14 \mathrm{~nm} / \mathrm{min}$, but the corrosion rate reduced to $3.37 \mathrm{~nm} / \mathrm{min}$ in this mixed slurry. The AFM micrographs of $\mathrm{Cu}$ surface before and after CMP with this slurry are shown in Fig. 3(a) and (b), respectively. In comparison with the AFM images, it shows the surface roughness could be reduced efficiently after CMP with the proposed slurry, $5 \mathrm{wt} \% \mathrm{U}-\mathrm{H}_{2} \mathrm{O}_{2}, 1 \mathrm{wt} \%$ GCA and $0.1 \mathrm{wt} \%$ BTA.

\subsection{EIS results}

The EIS results of $\mathrm{Cu}$ in the slurry of $5 \mathrm{wt} \% \mathrm{U}-$ $\mathrm{H}_{2} \mathrm{O}_{2}, 1 \mathrm{wt} \%$ GCA and $0.1 \mathrm{wt} \%$ BTA are presented by Nyquist and Bode plots as shown in Fig. 4(a) and (b), respectively. When $\mathrm{Cu}$ was 


\section{$\mathrm{Rq}=62.40 \mathrm{~nm}$}

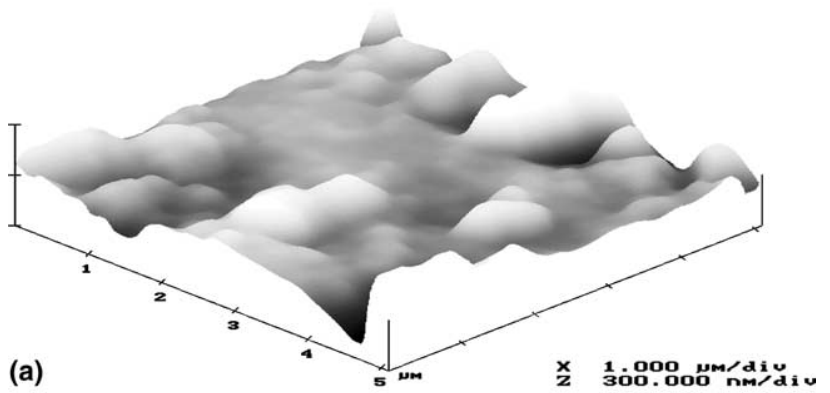

(a)

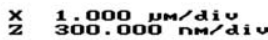

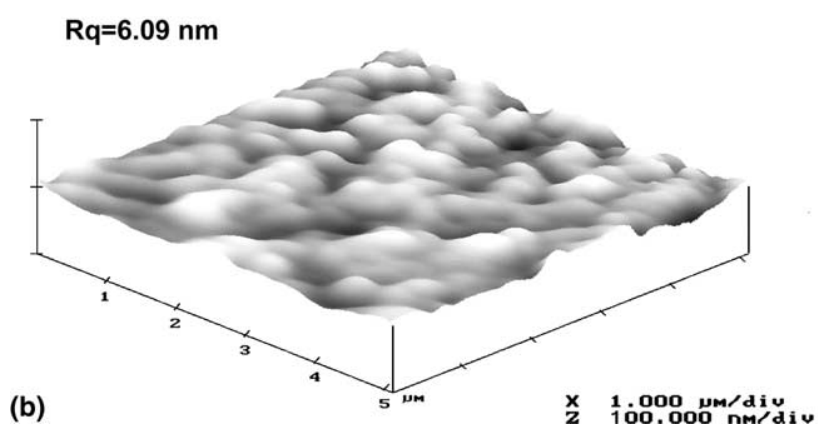

Fig. 3. AFM micrographs of $\mathrm{Cu}$ surface with roughness $\left(R_{\mathrm{q}}\right)$ : (a) before $\mathrm{CMP}$, and (b) after CMP with the mixed slurry, 5 wt $\% \mathrm{U}$ $\mathrm{H}_{2} \mathrm{O}_{2}, 1 \mathrm{wt} \%$ GCA and $0.1 \mathrm{wt} \%$ BTA.

immersed in the mixed slurry, a dual non-ideal semicircle response of Nyquist plot, shown in Fig. 4(a), could be found. As Griffin et al. [17] pointed out, this response is caused from the formation of the secondary conduction paths or discontinuities within the copper oxide layer at or near the incoherent precipitates. Thus, the constant-phase-element (CPE) was adopted in the equivalent circuit to fit the behaviors at the interface of $\mathrm{Cu}$ and slurry [6]. Furthermore, it has been reported the inductor response in the low frequency range is due to the adsorption or the evolution of gas on surface [18]. Therefore, our equivalent circuit for describing $\mathrm{Cu} \mathrm{CMP}$ would also contain the inductor element. In summary of the above facts, the electrochemical reactions at the interface of $\mathrm{Cu}$ and slurry would be simulated by the equivalent circuit of Fig. 5. As shown in this figure, the equivalent circuit consists of solution resistance $\left(R_{\mathrm{s}}\right)$, double-layer $\mathrm{CPE} \quad\left(\mathrm{CPE}_{\mathrm{dl}}\right)$, charge-transfer resistance $\left(R_{\mathrm{ct}}\right)$, passive-film CPE $\left(\mathrm{CPE}_{\mathrm{pf}}\right)$, passive-film resistance $\left(R_{\mathrm{pf}}\right)$ and adsorp- tion inductance $\left(L_{\mathrm{ad}}\right)$. The fitting results by use of CPEs, presented by the solid lines in Fig. 4(a) and (b), would approach those experiment results rather than those by use of capacitors.

The results are also displayed by the Bode plot in Fig. 4(b). According to ac impedance theory [18], the impedance at frequency $\mathrm{A}$ and $\mathrm{B}$, indicated by the dashed lines of Fig. 4(b), can be regarded as $R_{\mathrm{s}}+R_{\mathrm{pf}}+R_{\mathrm{ct}}, \quad$ and $\quad R_{\mathrm{s}}+R_{\mathrm{pf}}$, respectively, and the impedance at sufficiently high frequency, $10^{5} \mathrm{~Hz}$, is $R_{\mathrm{s}}$. Thus, we could calculate these resistances from the Bode plot. It was found that $R_{\mathrm{s}}$ approached $78.88 \Omega \mathrm{cm}^{2}$ when $\mathrm{Cu}$ was immersed into the mixed slurry, $5 \mathrm{wt} \% \mathrm{U}-\mathrm{H}_{2} \mathrm{O}_{2}, 1$ $\mathrm{wt} \%$ GCA and $0.1 \mathrm{wt} \%$ BTA. The polishing, however, increased $R_{\mathrm{s}}$ to $87.28 \Omega \mathrm{cm}^{2}$ due to the smaller fluid pathway between $\mathrm{Cu}$ surface and the pad. In addition, rise in $R_{\mathrm{pf}}$ and $R_{\mathrm{ct}}$ could be found with the increasing immersion time. The result indicated that the adsorbed BTA-layer and the formed oxide film inhibited the reactions continuously, and this caused the resistance to increase. As a 

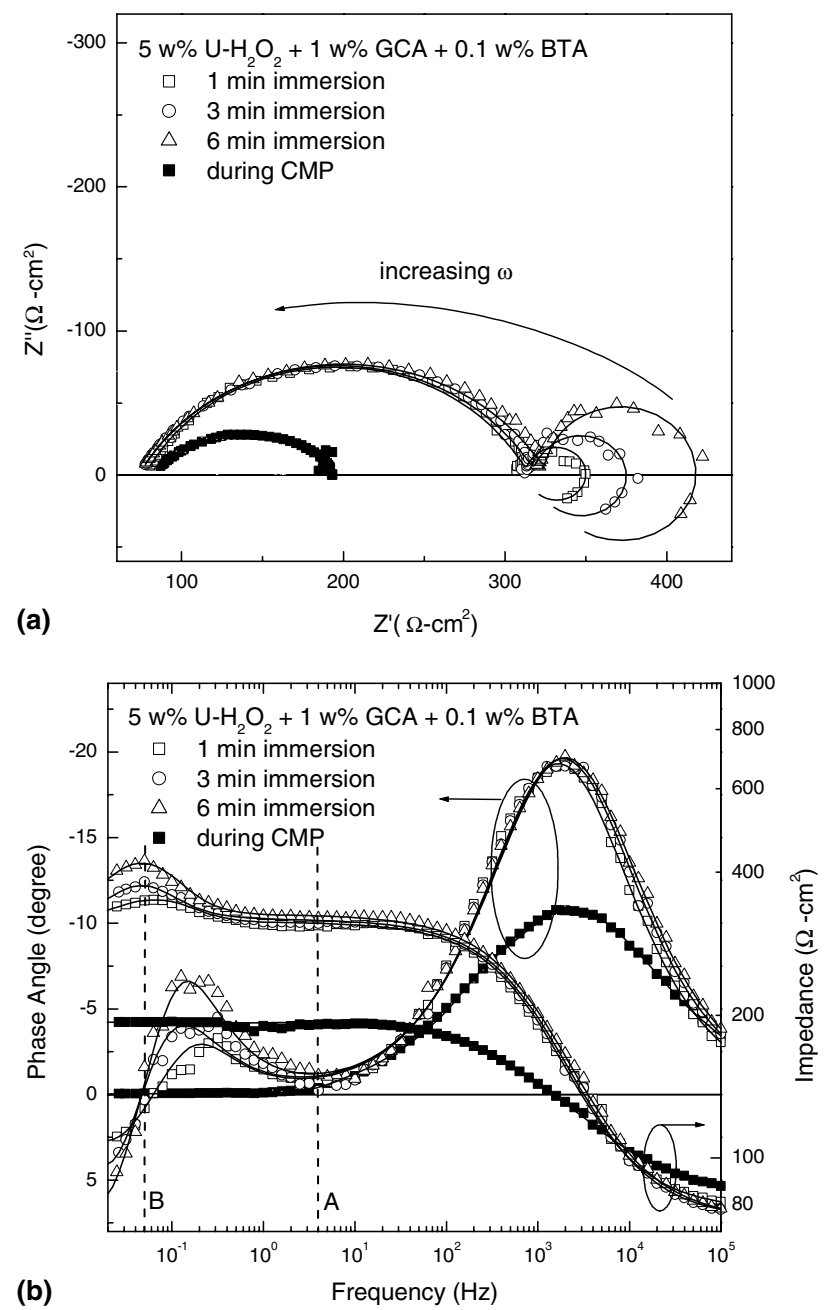

Fig. 4. Effects of immersion time and CMP on: (a) Nyquist plot and (b) Bode plot for $\mathrm{Cu}$ in $5 \mathrm{wt} \% \mathrm{U}-\mathrm{H}_{2} \mathrm{O}_{2}, 1 \mathrm{wt} \% \mathrm{GCA}$ and $0.1 \mathrm{wt} \%$ BTA slurry. Simulated results are represented by the solid curves (CMP: 5 psi and $100 \mathrm{rpm}$ ).

mechanical action of 5 psi and $100 \mathrm{rpm}$ was applied, the adsorbed layers and passive films were destroyed, and then $R_{\mathrm{pf}}$ and $R_{\mathrm{ct}}$ reduced substantially.

Moreover, the phase angle in Fig. 4(b) also shows that the high-frequency peak was related to the passivation while the low-frequency peak was affected by the surface reactivity. The former was lowered in most of the CMP duration, and the latter was raised with the increasing immersion time. Also, the positive phase-angle value, depending on the adsorption, increased with the immersion time and disappeared during CMP. All of the above results indicated that the formation of gas, the adsorption of BTA-layer and the generation of oxide film on the $\mathrm{Cu}$ surface could be illustrated well by the proposed equivalent circuit, and also the behaviors sensitive to the mechanical force could be investigated.

\subsection{Relationship between CPE and surface roughness}

In our observations, the passive film on $\mathrm{Cu}$ surface was a loose oxide layer, and its surface was often rough and porous. So a non-ideal capacitor 


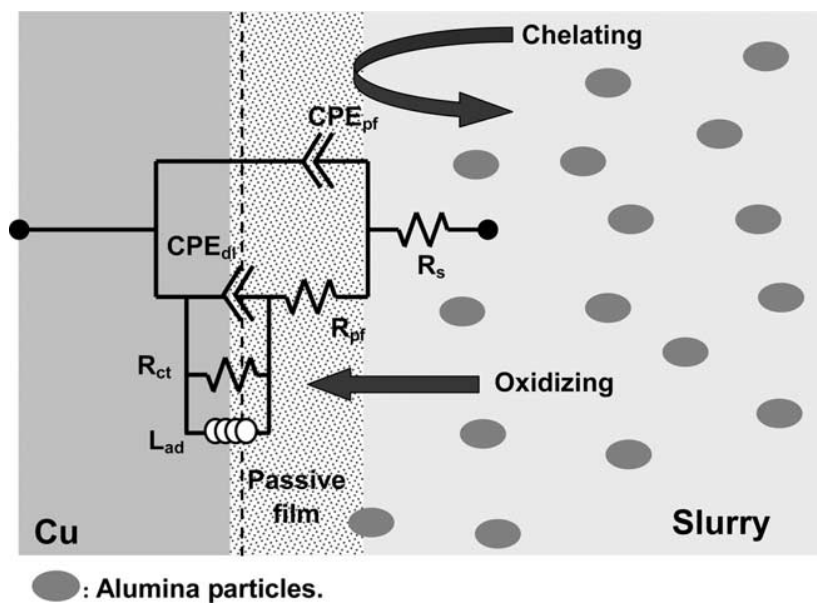

Fig. 5. Equivalent-circuit diagram and electrochemical characteristics used to fit the EIS results of Cu CMP as shown in Fig. 4.

was induced into the equivalent circuit for simulating the interface behaviors of $\mathrm{Cu}$ and slurry. The CPE herein was substituted for the ideal capacitor. The CPE impedance is written as [19],

$Z_{\mathrm{CPE}}=\left[T(\mathrm{j} \omega)^{n}\right]^{-1}$,

where $T$ is a general admittance function, $\mathrm{j}$ is the complex operator $(\sqrt{-1})$, and $n$ is an adjustable parameter that usually lies between 0.5 and 1 . When $n=1$, the CPE describes an ideal capacitance with the high planarization or homogeneities. For the case of $n=0.5$, a Warburg impedance relation is obtained; this impedance is associated with the concentration and the diffusion-related processes. Generally, the deviation from the ideal surface film, i.e. ideal capacitor, can be estimated by this adjustable parameter.

Fig. 6, containing the $\mathrm{Cu}-\mathrm{CMP}$ results by use of $\mathrm{U}-\mathrm{H}_{2} \mathrm{O}_{2}$-based slurries in Ref. [6], illustrates the dependence between the adjustable parameters and the roughness. In which, the parameters such as double-layer $\left(n_{\mathrm{dl}}\right)$ and passive film $\left(n_{\mathrm{pf}}\right)$ were included, and the roughness $\left(R_{\mathrm{q}}\right)$ was calculated by the AFM technique. Obviously, it exhibited that all of the $n_{\mathrm{pf}}$ values were lower than the $n_{\mathrm{d} 1}$ values and independent of the roughness. On the contrary, $n_{\mathrm{dl}}$ seemed further relevant to the $\mathrm{Cu}$ surface roughness $\left(R_{\mathrm{q}}\right)$. The reason was evident that $\mathrm{CPE}_{\mathrm{pf}}$ was involved in the porous passive layer while $\mathrm{CPE}_{\mathrm{dl}}$ was affected only by the $\mathrm{Cu}$ surface. As a result, the $n_{\mathrm{d} 1}$ value could provide a good index to monitor the planarization-performance on $\mathrm{Cu}$ surface. It was also found in Fig. 6 that the lowest surface roughness, $2.64 \mathrm{~nm}$, was obtained in the U$\mathrm{H}_{2} \mathrm{O}_{2}$ slurry mixed with $0.1 \mathrm{wt} \%$ BTA and $1 \mathrm{wt} \%$ $\mathrm{NH}_{4} \mathrm{OH}$ instead of GCA. Even though the slurry containing GCA was not the best choice for planarity, the addition of GCA still could enhance the slurry stability. As reported [20], a stable slurry is important for good CMP performance because it can not only improve CMP reliability but also reduce the defects of the surface after CMP.

\subsection{Surface potential and particle contamination}

Fig. 7 shows the zeta potentials of $\mathrm{Cu}$ and $\alpha$ $\mathrm{Al}_{2} \mathrm{O}_{3}$ particles as a function of $\mathrm{pH}$ in $0.1 \mathrm{wt} \%$ BTA solutions with or without $1 \mathrm{wt} \%$ GCA. The corresponding isoelectric points (IEPs), the $\mathrm{pH}$ of zero charge, of $\mathrm{Cu}$ and $\alpha-\mathrm{Al}_{2} \mathrm{O}_{3}$ without GCA were 0.725 and 9.109 , respectively. This meant that the $\mathrm{Cu}$ and $\alpha-\mathrm{Al}_{2} \mathrm{O}_{3}$ surfaces had opposite charges for $\mathrm{pH}$ values from 0.725 to 9.109 . The opposite charges resulted in the attraction, and then $\alpha$ $\mathrm{Al}_{2} \mathrm{O}_{3}$ particles would be easily deposited on $\mathrm{Cu}$ surface and difficultly removed. However, when 1 $w t \%$ GCA was added to the solutions, the IEPs of $\mathrm{Cu}$ and $\alpha-\mathrm{Al}_{2} \mathrm{O}_{3}$ reduced to 3.672 and 6.253 , respectively. Obviously, the $\mathrm{pH}$ range of $\mathrm{Cu}$ and $\alpha-\mathrm{Al}_{2} \mathrm{O}_{3}$ with opposite charges was shortened as shown in Fig. 7. This indicates that $\alpha-\mathrm{Al}_{2} \mathrm{O}_{3}$ deposition could be inhibited by use of GCA due to the electrostatic 


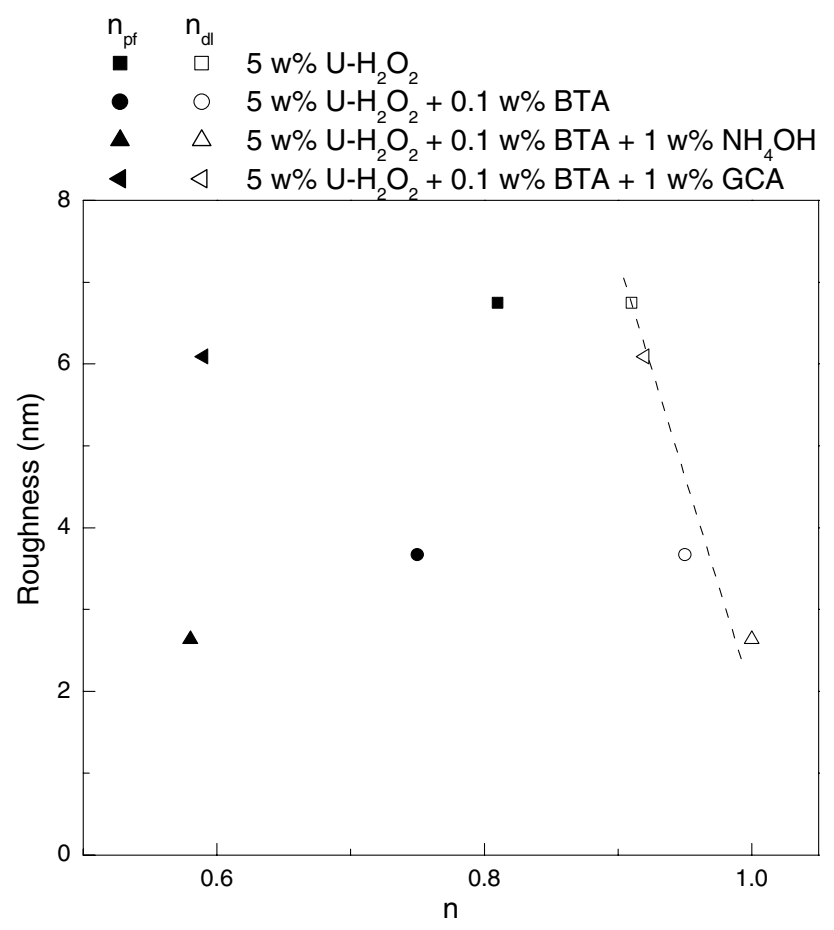

Fig. 6. Surface roughness vs. the adjusted parameters of passive film, $n_{\mathrm{pf}}$ (filled symbol) and double layer capacitances, $n_{\mathrm{dl}}$ (hollow symbol) in various slurries for $\mathrm{Cu} \mathrm{CMP}$ at 5 psi and $100 \mathrm{rpm}$.

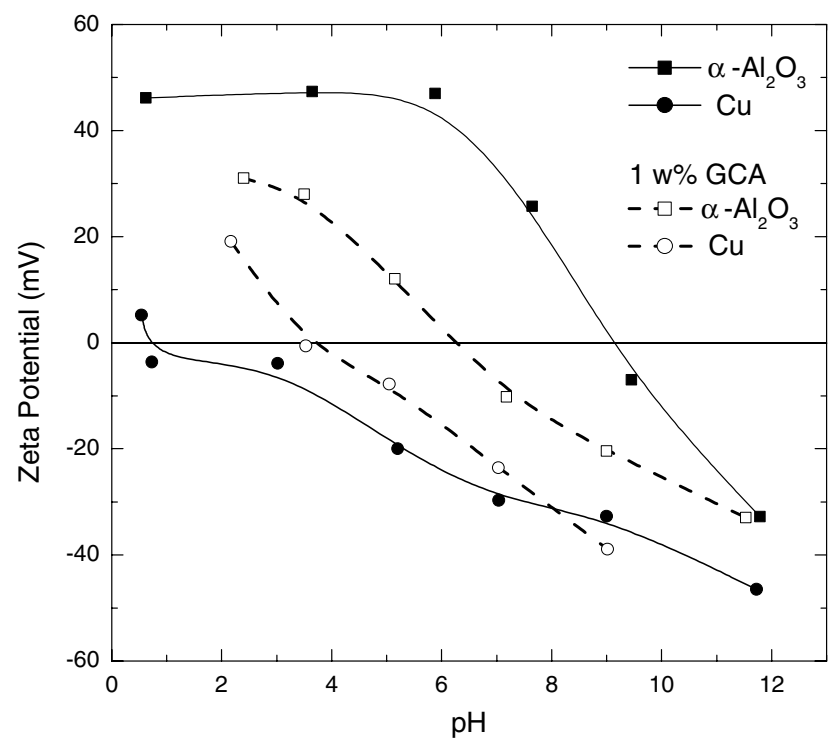

Fig. 7. Zeta potentials of $\alpha-\mathrm{Al}_{2} \mathrm{O}_{3}$ and $\mathrm{Cu}$ as a function of $\mathrm{pH}$ in $0.1 \mathrm{wt} \% \mathrm{BTA}$ solutions with or without $1 \mathrm{wt} \% \mathrm{GCA}$. 

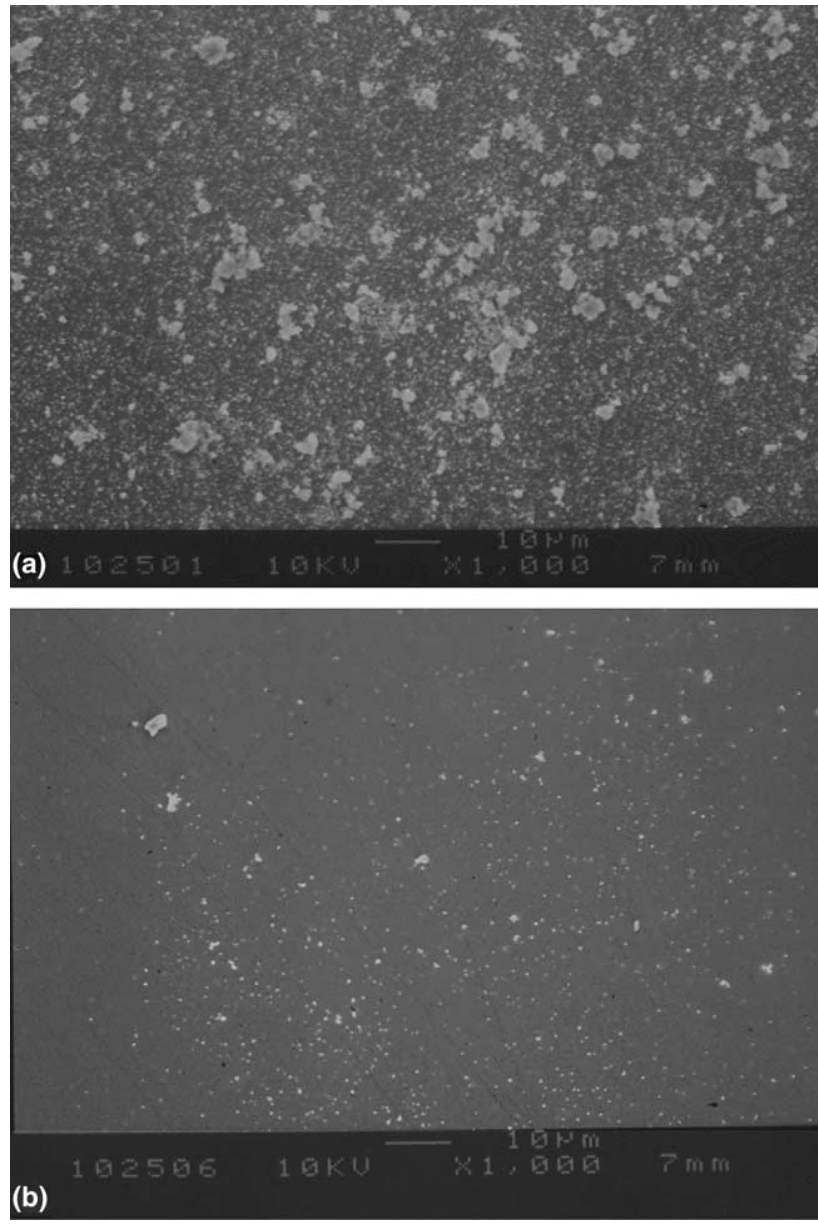

Fig. 8. SEM images of $\mathrm{Cu}$ samples dipped for $30 \mathrm{~s}$ in $5 \mathrm{wt} \% \alpha-\mathrm{Al}_{2} \mathrm{O}_{3}(300 \mathrm{~nm})$ and $0.1 \mathrm{wt} \%$ BTA slurries: (a) without GCA; (b) with 1 wt $\%$ GCA.

repulsion. Fig. 8 displays the SEM images of $\alpha$ $\mathrm{Al}_{2} \mathrm{O}_{3}$ contamination, shown by those white points, on $\mathrm{Cu}$ surface. It shows that a clearer $\mathrm{Cu}$ surface, with less $\alpha-\mathrm{Al}_{2} \mathrm{O}_{3}$ deposition, was obtained by use of the slurry with $1 \mathrm{wt} \%$ GCA. These SEM images supported the above results of zeta potential.

\section{Conclusions}

In this study, the effect of glycolic acid (GCA) on $\mathrm{Cu} \mathrm{CMP}$ was investigated by electrochemical methods, including titration, polarization and impedance experiments. The results showed that GCA could increase the stability of slurries by pre- venting the hydrogen-peroxide component from rapid decomposition. The electrochemical studies from polarization and impedance measurements verified that GCA could chelate with $\mathrm{Cu}$ and copper oxide on the polished surface in the existence of oxidants and inhibitors. Thus, the $\mathrm{Cu}-\mathrm{CMP}$ performance could be enhanced by use of GCA, and the $\mathrm{Cu}$ removal rate could achieve $594.14 \mathrm{~nm} / \mathrm{min}$ with a low surface roughness, $6.09 \mathrm{~nm}$, in the mixed slurry, $5 \mathrm{wt} \% \mathrm{U}-\mathrm{H}_{2} \mathrm{O}_{2}, 1 \mathrm{wt} \%$ GCA and $0.1 \mathrm{wt} \%$ BTA. In addition, a deliberate equivalent circuit for $\mathrm{Cu}-\mathrm{CMP}$ system was proposed. The fitting results of EIS showed that the adjustable parameter of double-layer CPE $\left(n_{\mathrm{dl}}\right)$ would depend on the surface roughness and could be regarded as an index 
to CMP planarization. The slurry with GCA still could result in the electrostatic repulsion between $\mathrm{Cu}$ surface and $\alpha-\mathrm{Al}_{2} \mathrm{O}_{3}$ over a $\mathrm{pH}$ range larger than that without GCA. Therefore, the addition of GCA into copper slurries could efficiently decrease particle contamination and easily enhance the post-CMP cleaning process.

\section{Acknowledgements}

The authors would like to thank the National Science Council in Taiwan for financially supporting this research under Contract No. NSC 932214-E-149-001. Also, the authors are pleased to acknowledge the help extended by Northern Taiwan Institute of Science and Technology and National Taiwan University.

\section{References}

[1] H. Xiao, Introduction to Semiconductor Manufacturing Technology, Prentice-Hall, Inc., New Jersey, 2001.

[2] J.M. Steigerwald, R. Zirpoli, S.P. Murarka, D. Price, R.J. Gutmann, J. Electrochem. Soc. 141 (1994) 2842.

[3] F.B. Kaufman, D.B. Thompson, R.E. Broadie, M.A. Jaso, W.L. Guthrie, D.J. Pearson, M.B. Small, J. Electrochem. Soc. 138 (1991) 3460.
[4] M. Ziomek-Moroz, A. Miller, J. Hawk, K. Cadien, D.Y. Li, Wear 255 (2003) 869.

[5] T. Du, Y. Luo, V. Desai, Microelectron. Eng. 71 (2004) 90.

[6] T.H. Tsai, Y.F. Wu, S.C. Yen, Appl. Surf. Sci. 214 (2003) 120.

[7] V.B. Kaufman, R.C. Kistler, US Pat. 5,954,997, 1999.

[8] T.C. Hu, S.Y. Chiu, B.T. Dai, M.S. Tsai, I.C. Tung, M.S. Feng, Mater. Chem. Phys. 61 (1999) 169.

[9] L. Zhang, S. Raghavan, S. Meikle, G. Hudson, J. Electrochem. Soc. 146 (1999) 1442.

[10] J.M. Steigerwald, S.P. Murarka, R.J. Gutmann, D.J. Duquette, Mater. Chem. Phys. 41 (1995) 217.

[11] K. Yang, S. Avanzino, C.M.C. Woo, US Pat. 6,143,656, 2000.

[12] S. Aksu, F.M. Doyle, J. Electrochem. Soc. 149 (2002) B340.

[13] M. Hariharaputhiran, J. Zhang, S. Ramarajan, J.J. Keleher, Yuzhuo Li, S.V. Babu, J. Electrochem. Soc. 147 (2000) 3820.

[14] S. Aksu, F.M. Doyle, J. Electrochem. Soc. 149 (2002) B352.

[15] H.S. Kuo, W.T. Tsai, J. Electrochem. Soc. 147 (2000) 149.

[16] T.H. Tsai, S.C. Yen, Appl. Surf. Sci. 201 (2003) 190.

[17] A.J. Griffin, F.R. Brotzen, C.F. Dunn, J. Electrochem. Soc. 141 (1994) 3473.

[18] J.R. Macdonald, Impedance Spectroscopy, Wiley, New York, 1987.

[19] R. Babic, M.M. Hukovic, A. Jukic, J. Electrochem. Soc. 148 (2001) B146.

[20] L. Zhang, S. Raghavan, M. Weling, J. Vacuum, Soc. Technol. B 17 (1999) 2248. 